\title{
Feminist Analysis of the Movie "Butterfly Jun"
}

\author{
Wanqing Yuan \\ Xi'an University, Xi'an, China, 710065
}

Keywords: "Butterfly Jun"; post-colonial feminism; discourse subversion; stereotype; materialization

\begin{abstract}
Butterfly Jun" is Huang Zhelen's famous work. This work not only makes Huang Zhelun win the best drama award of Tony, but also won great reputation for Huang Zhelun. From then on, the American Chinese writer entered. The eyes of American literary critics have been well received. At the same time, domestic scholars have begun to turn their attention to the study of "Butterfly Jun". This is not only because "Butterfly Jun" is a winning work of a Chinese writer, but also because of the various major research topics of great significance in this work. Among them, post-colonialism is crying out in the works, and most scholars at home and abroad also analyze from the perspective of this research. In addition, feminism is also an important topic of research and significance. This article will link post-colonialism and feminism, using the post-colonial feminist theory to interpret Butterfly Monarch, trying to discover another layer of thought-provoking feminist proposition from the post-colonial theme.
\end{abstract}

\section{Introduction}

In the history of American literature, there are many stars in the history of American literature. There are many famous works of world influence. It is very difficult for minority literature to earn a place in the mainstream literary world centered on whites. As a Chinese American writer, Huang Zhelun's achievements It is eye-catching. In 1988, "Butterfly Jun", which established Huang Zhelun's position in the American theater world, was staged on Broadway. Huang Zhelun also won the Tony Award for Best Drama Award. The story of "Butterfly Jun" is based on a piece of international news at the time and contacted the famous opera "Madame Butterfly". "Butterfly Jun" mainly tells a rather bizarre story. A French diplomat falls in love with a Chinese actress, and this actress is not only a spy, but also a man. Huang Zhelun believed that it contained a deeper meaning, so he linked it to Madame Butterfly and wrote a story with a completely different ending from Madame Butterfly. Therefore, the drama "Butterfly Jun" has a more profound connotation, but also involves the theme of post-colonialism and feminism. This paper intends to use post-colonial feminist theory to conduct research and analysis ${ }^{[1]}$.

\section{Overview of post-colonial feminism}

The post-colonial theory developed after the 1970s was a cultural theory and academic trend of colonialism. Unlike colonialism, post-colonialism no longer focused on political, economic, and military intrusion, but instead turned to Infiltration of ideology and culture. The distinctive feature 
of postcolonial cultural theory is to completely change the relationship between "subject/other" in colonial culture, which is a discourse of a vulnerable group. Feminist criticism emerged in the middle of the 20th century, prompting it to produce a feminist movement in the early period. As a vulnerable group in the male subject environment, women have been trying to subvert the mainstream culture in the feminist movement, changing their marginal status and mastering their own right to speak ${ }^{[2]}$.

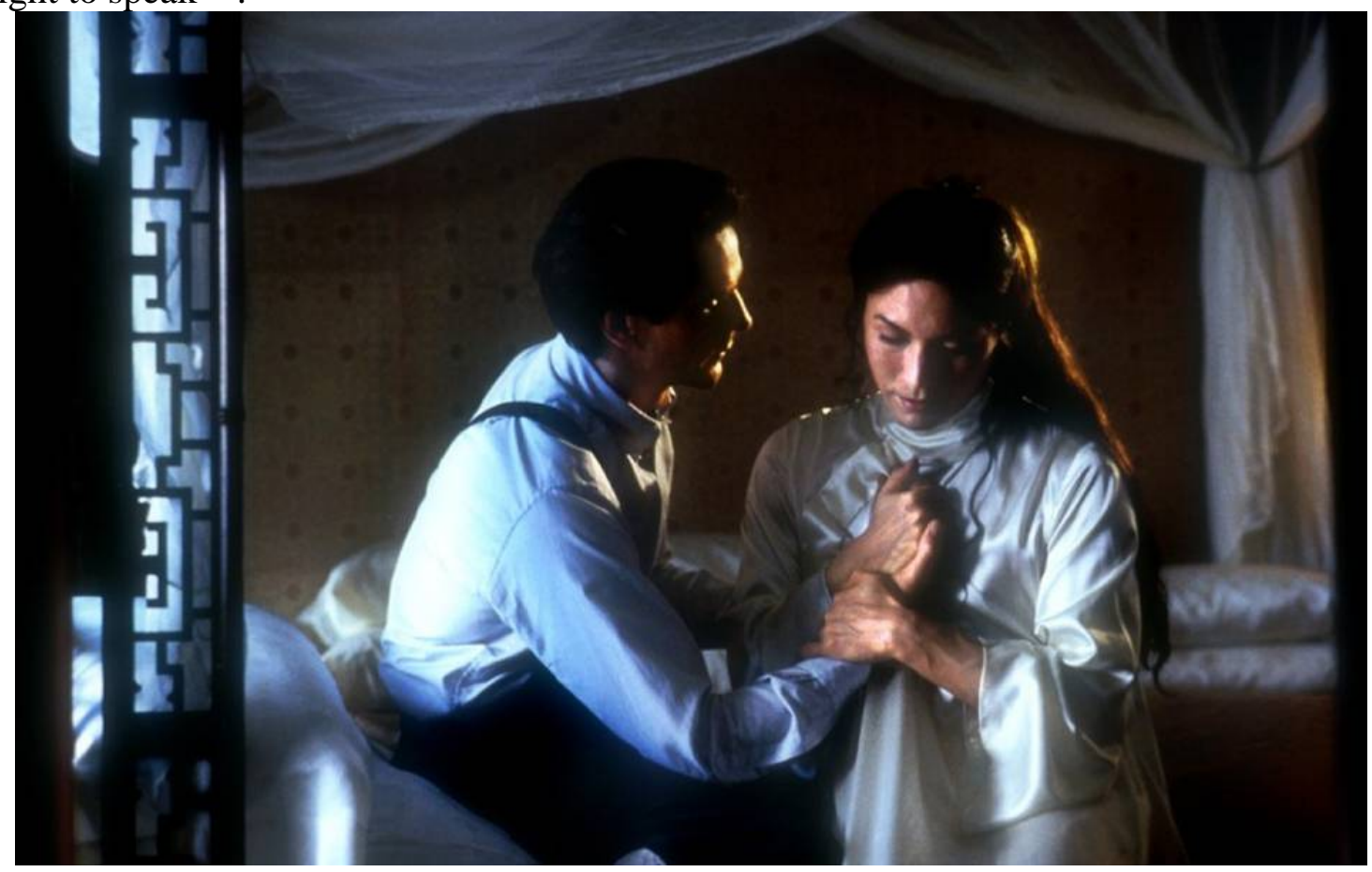

Figure 1: Movie Stills: Huang Zhelun's superb acting

Both feminism and post-colonialism are representatives of the "minority discourse", which are voiced by a marginalized minority of oppressed groups in the "other" position, each opposing similar oppression, and therefore post colonialism and feminism they have a natural commonality and naturally combine to form post-colonial feminism. Zhao Ryufang said in the book "Post Colonialism": "Here, feminism and post-colonialism are not a parallel relationship, but a positive relationship. Feminism modifies post-colonialism and refers to post-colonial criticism from a female perspective. It is an important part of postcolonial theory. The connotation and innovation of feminist post colonialism comes from the intersection of feminism and post colonialism. In general, it can be divided into two aspects: First, the post colonialism of feminism Criticism of the doctrine, and second, feminist criticism in the post-colonial field. The focus of this paper is on the second aspect, and specifically addresses the encounter and status of women in post-colonial international relations ${ }^{[1]}$.

\section{Post-colonialism in "Butterfly Jun"}

Post colonialism mainly studies the aggression and oppression of the colonial countries on the ideological, cultural, and ideological aspects of the former colonial countries. Post-colonialism relies on Foucault's doctrine of "discourse" and "power". In international relations, "power" stands for "discourse." Since the modern times, the West has entered the capitalist society under the catalysis of the industrial revolution. The economy and military power are strong. Therefore, after the end of colonial rule, the West, which is stronger than the East, seized the right to speak, leading to the "soundlessness" of the East. The East, which lost its right to speak, was thus marginalized and 
placed in the position of the other. Therefore, post colonialism denies all dominant narratives because all dominant narratives are Eurocentric or Western centrism, while Western centrism uses a specific perspective of power to examine East-West relations.

\section{1 "Oriented" Orientalization}

In the book Orientalism, Said that the so-called "orientation" of the Westerners is not so much a real existence as it is an "imaginative construction" of the "other", or A kind of "strategic construction" in which the West strengthens the "self" superiority. In "Butterfly Jun", French diplomat Galina expressed his understanding of the East and the East: "No matter who it is, as long as it shows strong power and power, the Orientals are willing to be with him....Oriental People always give in to a stronger force." Song Lichen reprimanded the West in court: "The West has an international rape mentality in the East." "The West thinks he is male-a huge gun, a huge industry, big The pen's banknotes_-so the East is feminine-weak, refined, poor... but good at art, full of incredible wisdom—all are women's wisdom.”

\subsection{Subversion of the discourse power of the East and the West}

"Butterfly Jun" is a parody of the famous opera "Madame Butterfly", but it subverts the discourse power of the East and the West, and has aroused people's post-colonial discussion on the identity and discourse of the East. The autumn and autumn mulberry in "Madame Butterfly" is a typical oriental traditional woman in the eyes of Westerners. She is gentle and beautiful and weak, like a silk flower, and he is the only one behind Pinkerton. Such an autumn and autumn sang is not independent of her own will, even if she has her own ideas cannot be expressed, and even if it is said, the voice is very weak, in front of Pink, a powerful man from the Western world. Neglected, that is to say, the right to speak of the Eastern woman in autumn and autumn has been deprived by Westerners. Song Liming began to cover her face with sadness and cry ${ }^{[3]}$.

However, Song Lizhen in "Butterfly Jun" plays the same role as Qiu Qiu Sang, but it is quite different from Qiu Qiu Sang. Song Lizhen used the stereotypes of the Eastern women in the Western worldview and their illusions about the East to gain intelligence and achieve her own goals. On the surface, Song Lizhen succumbs to Galima from France. She looks up and respects this Western man and tries to play the "butterfly" in the heart of Galima, but in fact it is that Garmin succumbs to Song Lizhen's elaborate disguise. "Butterfly" representation. At this time, Song Lizhen was no longer a weak representative of the East, and the incarnation became a symbol of power. In contrast, Galima became a loser of power loss. In addition, Song Lizhen also steals state secrets by acquiring Gilliam's trust, placing Galima in the double cage of body and mind, and depriving him of his right to speak, and sending out the strongest voice of the Orientals.

\section{Feminism in "Butterfly Jun"}

Although the feminist movement has a long history, women in today's society are still an oppressed and discriminated group. Among the female groups, the encounters of oriental women are more obvious.

Westerners have a stereotyped impression of Eastern women who believe that Eastern women are shy, weak, conservative, have no sense of independence, and succumb to powerful Western men.

Galima and Song Lizhen met initially, and Galima saw that Song Lizhen was playing Madame Butterfly. Huang Zhelun used the technique of "playing in the play" and "playing in the play" to let Galima he expresses his feelings at that time, which made Gilliam's words more intuitive and 
persuasive. "They said that in the opera, the voice is everything. This may be the reason why I have never enjoyed the opera before. This... this butterfly has no voice - but she is elegant and weak... I believe this girl. I believe her pain, I want to hug her into my arms - how weak she is, even, I can protect her, take her home, indulge her, and pamper her, until she smiles." Galima the remarks revealed that he naturally linked Song Lijun, an oriental woman, to the consistent image of Qiu Qiu Sang in "Madame Butterfly". It is natural to assume that Song Lizhen is such a beautiful and shy, weak and conservative typical oriental woman ${ }^{[3]}$.
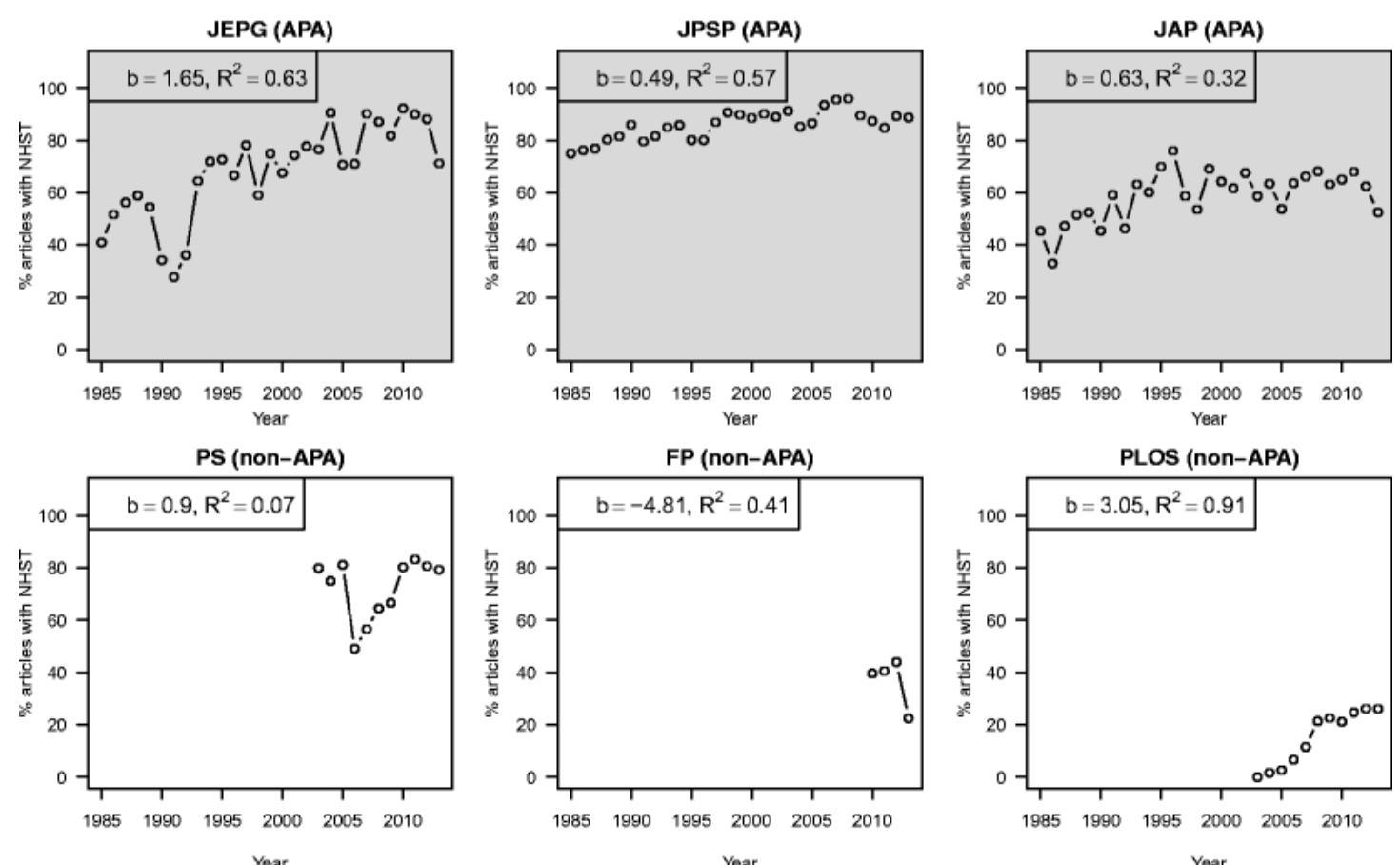

Figure 2: Development statistics of feminism in recent years

\section{Conclusions}

Although the feminist movement has a long history, women in today's society are still an oppressed and discriminated group. Among the female groups, the encounters of oriental women are more obvious. In "Butterfly Jun", Song Lizhen plays an oriental woman. The dual oppression of this identity can be interpreted from post-colonialism and feminism. On the one hand, because of Song Lizhen's oriental identity, she suffers from Westerners. Unfair treatment; on the other hand, Song Lizhen's oriental female identity, this identity caused her to suffer the oppression of Galima, a Western male. Using post-colonial feminism to analyze it can deepen and more completely explore the relationship between East and West, and provide a possibility for finding effective solutions.

\section{References}

[1] Huang Y. Analysis of feminist narrative mode based on the "butterfly dream" and " Rebecca" [J]. Journal of Jiamusi Education Institute, 2017.

[2] Hicknerjohnson C. The Feminist Spectator in Action: Feminist Criticism for the Stage and Screen by Jill Dolan (review) [J]. Feminist Teacher, 2016, 26.

[3] Wang S Y. Dilemma and rescue: a feminist analysis of Woman-Demon-Human[J]. Journal of Zhenjiang College, 2016. 